University of Wollongong

Research Online

Senior Deputy Vice-Chancellor and Deputy Vice- Senior Deputy Vice-Chancellor and Deputy ViceChancellor (Education) - Papers

$1-1-2020$

\title{
Meeting Students Where They Are: Just in Time Embedded Delivery of Information and Digital Literacy Skills
}

\author{
Amy Hardy \\ University of Wollongong, amym@uow.edu.au \\ Clare McKenzie \\ University of Wollongong, claremc@uow.edu.au
}

Follow this and additional works at: https://ro.uow.edu.au/asdpapers

Part of the Arts and Humanities Commons, and the Social and Behavioral Sciences Commons

\section{Recommended Citation}

Hardy, Amy and McKenzie, Clare: Meeting Students Where They Are: Just in Time Embedded Delivery of Information and Digital Literacy Skills 2020, 64-72.

https://ro.uow.edu.au/asdpapers/742 


\title{
Meeting Students Where They Are: Just in Time Embedded Delivery of Information and Digital Literacy Skills
}

\begin{abstract}
At the University of Wollongong (UOW) Library we have been exploring ways to deliver information and digital literacy resources at point of need for students. Aligned with the University's strategic direction, the Future Ready Library Strategy points to a digital first mindset and its application to services and resources offered to the UOW community. Combined with the need to embrace the real life challenges faced by higher education students in Australia today, this has led us to develop a suite of digital learning objects in collaboration with teaching academics that can be delivered at scale, enabling a sustainable way to target student needs. In this article, we discuss the drivers that have brought UOW Library to this point and outline the model for learning and teaching support for our academic community into the future.

\section{Keywords}

uowlibrary

Disciplines

Arts and Humanities | Social and Behavioral Sciences

\section{Publication Details}

Hardy, A. \& McKenzie, C. 2020, 'Meeting Students Where They Are: Just in Time Embedded Delivery of Information and Digital Literacy Skills', International Information and Library Review, vol. 52, no. 1, pp. 64-72.
\end{abstract}




\title{
Column Title: Perspectives on Public Services
}

Column Editor: Andrea Falcone, Dean of the W. Frank Steely Library, Northern Kentucky University, Highland Heights, KY falconea1@ nku.edu

This column examines advances in public services internal and external to libraries. The focus is on how public services, such as instruction and education, programming, research consulting, and circulation, evolve and impact users. The strength of the column is its broad, international focus and contributors are encouraged to explore issues and recent advances in public services relevant to their geographical region, as well as the larger, global audience. Interested authors are invited to submit proposals and articles to the column editor at falconea1@ nku.edu.

\section{Meeting students where they are: just in time embedded delivery of information and digital literacy skills}

\author{
AMY HARDY \\ Acting Team Leader Liaison Services, University of Wollongong Library, Australia \\ amym@uow.edu.au \\ CLARE MCKENZIE \\ Associate Director Learning \& Engagement, University of Wollongong Library, Australia \\ clare_mckenzie@uow.edu.au
}

\begin{abstract}
:
At the University of Wollongong (UOW) Library we have been exploring ways to deliver information and digital literacy resources at point of need for students. Aligned with the University's strategic direction, the Future Ready Library Strategy points to a digital first mindset and its application to services and resources offered to the UOW community. Combined with the need to embrace the real life challenges faced by higher education students in Australia today, this has led us to develop a suite of digital learning objects in collaboration with teaching academics that can be delivered at scale, enabling a sustainable way to target student needs. In this paper we discuss the drivers that have brought UOW Library to this point and outline the model for learning and teaching support for our academic community into the future.
\end{abstract}

\section{Keywords}

Liaison librarians; Digital Learning Objects; digital transformation;

\section{Introduction:}

The University of Wollongong Library has been deliberately reducing face to face information literacy instruction over the past decade. Down from more than 700 classes per year conducted between 2007-2009, last year the number was 35 and we expect this to decrease further as time goes on. Instead, we are leveraging relationships with the academic community to provide targeted, just in time, information and digital literacy resources for students within their learning management system and on a range of other online platforms. 
This article outlines our journey to this point and provides a model for a sustainable and scalable learning and teaching support service into the future.

\section{Australian Higher Education Context}

The majority of universities in Australia are public and rely heavily on federal government funding (Department of Education, 2018). Policy restraints mean that all publicly funded universities deliver the full spectrum of degrees from undergraduate to doctoral level and are dependent for funding on both student enrolments and outcomes such as research grants, outputs and higher degree research (HDR) completions (Davis, 2013). Funding for student enrolments has been frozen at 2017 levels until 2020 (Bexley, 2019) and universities choosing to enrol over these student numbers do not receive government financial support for this.

Universities offset some of these funding restraints with increasing numbers of full fee paying international students. Many universities rely on these full fee paying students to ensure continued growth and development of services and facilities across the entire student body (Min \& Falvey, 2018).

The effects of these policy environment pressures play out in the student experience. Increasing the numbers of students coming to university increases the diversity, backgrounds and ongoing needs of those students. The dilemma is how to foster and sustain personalised student experiences, at scale, within the constraints of shrinking budgets such as those faced by Australian universities.

$80 \%$ of Australian domestic students are working as well as studying, with one in three students regularly missing class because they are working (Universities Australia, 2018). Students are time shifting their opportunities to interact and engage with the universities and are increasingly interacting with us online even if they are on campus or enrolled as face to face students.

Technology enables obvious opportunities in this space, however, providing a meaningful experience in an online environment is challenging.

Within this context, student retention is a critical issue for universities. Personalised, student centric approaches to support services are clear indicators of student success (Department of Education and Training, 2017) and Australian universities are firmly focused on ways to improve student experience and retention.

The University of Wollongong (UOW) operates within this national higher education context. Located about a 90 minutes drive south of Sydney, Wollongong is a regional centre with strong links to industry and is a gateway to the south coast of New South Wales. The University is consistently ranked highly for student outcomes and quality of graduates, alongside strong research performance (University of Wollongong, 2019). At the time of writing, UOW has close to 36,000 students enrolled across 365 degree programs on multiple campus locations. The majority of students attend the Wollongong campus or one of our other regional or metropolitan centres, however, just over $20 \%$ of those students are at offshore campus locations including Dubai, Hong Kong and Singapore (University of Wollongong, 2019a). These multiple campus

\footnotetext{
(C) Amy Hardy and Clare McKenzie

Address correspondence to Amy Hardy, Acting Team Leader Liaison Services, University Library, University of Wollongong, Northfields Avenue, Wollongong, NSW 2522 Australia. E-mail: amym@uow.edu.au or Clare McKenzie, Associate Director Learning \& Engagement, University Library, University of Wollongong, Northfields Avenue, Wollongong, NSW 2522 Australia. E-mail: clare_mckenzie@uow.edu.au.
} 
locations provide their own unique flavour to the UOW experience, but typically, share core business functionality such as IT and Library services and operate under policies and procedures that are aligned with UOW's vision and purpose.

The University is developing an online-only teaching offering to sit alongside the increasingly hybrid delivery versions of the traditional face to face mode. As most of our students interact with us online in some way, even if they are fully enrolled on campus, business units are being tasked to develop service models that include access points beyond traditional opening hours and channels of communication; requiring collaboration across units at a scale untested so far in our institutional history. Constrained budgets and the need to personalise service at scale means moving support services into the online space to maximise the student experience. Effective cross institutional triaging of these services to ensure students get access to the most relevant information for their needs with as few clicks as possible is a critical wicked problem currently confronting us.

The Library has been well placed to respond to this, having had a focus on unmediated access to resources and information as well as extended on-campus opening hours for many years. This has been formalised in recent years through a digital first focus in our strategic and operational plans.

\section{UOW Library Context}

Like many other academic libraries, the campus library at Wollongong has seen significant decreases in circulation of the physical collection over time, combined with an increase in visits to the building as students seek study spaces and associated infrastructure. In the eight years from 2010, student borrowings of physical items from Wollongong campus library fell from 276,000 to just 56,000 , a drop of almost $80 \%$. This has prompted the Library to reduce the space taken up by the physical collections through digitisation, reduction, and off-site storage of low use resources.

The collection development policy states a position and commitment towards an e-preferred model for acquisitions and encourages use of electronic materials for core and recommended readings to support anywhere, anytime access to resources (University of Wollongong, 2017). At the same time, a 2015 student survey revealed significant dissatisfaction with the interfaces or accessing Library resources. Improvements to the discovery layer prompted by these results led to a significant increase in usage from 2017 onwards.

\section{Information literacy and Liaison Services}

From 2007-2009 UOW liaison librarians taught over 700 face to face information literacy classes to more than 18,000 students per year. In 2011, incoming Vice-Chancellor Professor Paul Wellings signalled a shift in strategic priorities to drive research activity, saying that UOW should "aspire to create an environment where Wollongong is in the top 1 per cent of Universities in the world" (Hall, 2011), with a particular goal to increase recognition of the University of Wollongong in the international research community. For the Library, where

(C) Amy Hardy and Clare McKenzie

Address correspondence to Amy Hardy, Acting Team Leader Liaison Services, University Library, University of Wollongong, Northfields Avenue, Wollongong, NSW 2522 Australia. E-mail: amym@uow.edu.au or Clare McKenzie, Associate Director Learning \& Engagement, University Library, University of Wollongong, Northfields Avenue, Wollongong, NSW 2522 Australia. E-mail: clare_mckenzie@uow.edu.au. 
learning and teaching excellence held focus and capabilities at that time, a turning point was in sight as we refocused our priorities to align with the institutional direction.

Other than a slight uptick in 2015, face to face classes have been in steady decline since 2009 . By 2017 we were down to 67 information and digital literacy classes taught by liaison librarians in the year and this halved again in 2018 to 34 classes in total (some delivered online through Adobe Connect). This number is expected to further decline for 2019 (see Figure 1).

Figure 1: Information literacy classes at UOW Library 2007-2018

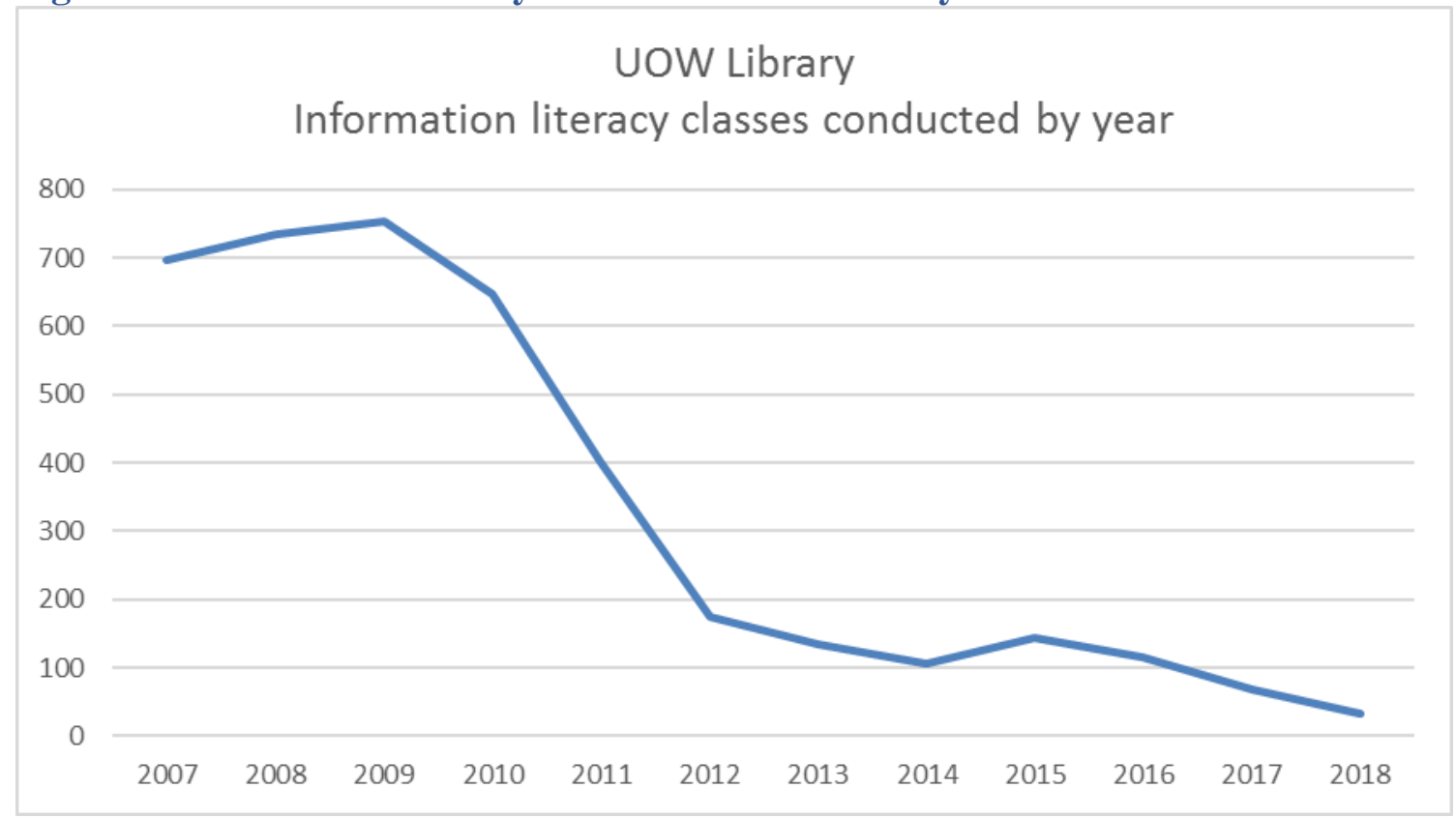

There have been significant challenges and bumps in the road along the way. Faculty teaching staff highly valued the fact that a librarian would teach in their subjects from year to year meaning that initial conversations about a different approach were often challenging. In the early years, liaison librarians were stretched to their limits, and struggled to take on new types of work. Liaison (then Faculty) librarians supported teaching and learning through the delivery of information literacy classes and collection development functions. During this period only one librarian supported research impact and analysis. The shift in University priorities and the directive for academics to be 'research active' necessitated more support for researchers, and our message to teaching staff became mixed.

Following from this increased demand for supporting research, an outreach team was formed in 2011 with the intention to have discussions with all academics about how we might support them with their (mostly research) priorities. A Research Analysis and Impact Service (RIAS) was launched, which included providing reports about the research impact of individual academics, high level literature scans, and journal impact reports to support strategic publishing. Crucially, the new focus on research support services was the beginning of our understanding about the 
value of focused conversations, active listening and relationship building with the academic community to inform the development of library services.

During this period the Liaison Services team continued to teach information literacy face to face, however, the number of classes decreased every year. To do the new work of supporting research, it was essential to reduce the number of tutorial teaching instances by negotiating to teach into larger lectures instead as it was no longer sustainable to teach into several tutorials for the same subject. At the same time, the changing nature of student life required we rethink equitable ways to provide information and digital literacy information and skills, rather than relying on the traditional idea that all students are coming onto campus for lectures. For smaller cohorts we took a blended / flipped approach wherever possible. The conversations we had with Faculty teaching staff were often difficult, and changing attitudes and showing the value of online rather than face to face was not always easy for academic staff or librarians.

The main concern from librarians and academics alike, was that students would not learn information literacy skills as effectively online. However, the literature shows that this is not necessarily the case. The benefits of meeting students where they are cannot be underestimated (Maddison 2013) and a systematic review comparing blended, online and face-to-face information literacy instruction has indicated no difference between face-to-face and online instruction using a pre and post testing methodology (Weightman, Farnell, Morris, Strange, \& Hallam, 2017).

As we progressed, we continued to develop our understanding of the value of working with and listening to academics about their priorities, as well as their students' needs. Many agree that increased collaboration between librarians and academic teaching staff is essential to improving student's information literacy skills (Yevelson-Shorsher \& Bronstein, 2018, Farrell \& Badke, 2015) and Bapte (2019) goes as far as saying information literacy outcomes cannot be achieved without this collaborative effort.

Faculty teaching staff do not always have a clear understanding of their students' needs in relation to information and digital literacy and rely heavily on the expertise of librarians, partly because over many years, libraries have successfully managed to hold onto a siloed, expert knowledge in this area (Cowan 2014). However, the context that an academic can provide to students when connecting these skills to subject material and subsequent assessment tasks is invaluable for understanding why they are learning the skill in context to their discipline. Farrell \& Badke (2015) call this 'situated learning' and say that academics are key to integrating IL into the curriculum as they understand the information related behaviours key to their particular discipline. This is especially important for students who are learning online or in blended environments, or unable to attend face to face information literacy classes for other reasons (Maddison 2013). Situating information and digital literacy content in the LMS with context provided by the lecturer or subject coordinator provides an authentic and engaging learning environment.

\section{Future Ready Library Services}

\footnotetext{
(C) Amy Hardy and Clare McKenzie

Address correspondence to Amy Hardy, Acting Team Leader Liaison Services, University Library, University of Wollongong, Northfields Avenue, Wollongong, NSW 2522 Australia. E-mail: amym@uow.edu.au or Clare McKenzie, Associate Director Learning \& Engagement, University Library, University of Wollongong, Northfields Avenue, Wollongong, NSW 2522 Australia. E-mail: clare_mckenzie@uow.edu.au.
} 
In February 2018, Library leadership delivered a strategic roadmap document entitled 'The Future Ready Library: UOW Library 2021' (University of Wollongong Library, 2018). This roadmap is focused on skills for the future and was influenced and informed by interactions with a wide range of clients and stakeholders from the UOW community and followed an extensive analysis of national and global trends of academic libraries. The focus on rapidly changing practices in the development and application of technology from documents such as the NMC Horizon Report - Library edition 2017; and SCONUL Report 2017 - Mapping the Future of Academic Libraries was interpreted in the context of the University of Wollongong. This resulted in an overarching guiding principle for the future, requiring all Library staff and services to apply an 'online first' mindset. This principle has since evolved to become digital first and includes a set of guiding principles (See Table 1).

Table 1 - Digital First Principles at UOW Library

\begin{tabular}{|c|c|}
\hline Design with the user & $\begin{array}{l}\text { User-centred design starts with getting to know and } \\
\text { understand the people you are designing for through } \\
\text { conversations, observation and co-creation. Consider } \\
\text { universal design principles wherever possible for the best } \\
\text { user outcomes. }\end{array}$ \\
\hline Empower users of digital & $\begin{array}{l}\text { Ensure investment addresses the needs of students, } \\
\text { academics and researchers. Strive for seamless anytime, } \\
\text { anywhere, any device access to University services. } \\
\text { Facilitate personal agency through self-service, reduced } \\
\text { manual intervention and de-duplication of effort. }\end{array}$ \\
\hline Ease of use & $\begin{array}{l}\text { Minimise technical complexity and diversity. Strive to } \\
\text { actively simplify digital architecture and infrastructure to } \\
\text { improve the user experience and to minimize overheads. }\end{array}$ \\
\hline Be collaborative & $\begin{array}{l}\text { Digital initiatives will challenge the traditional siloed } \\
\text { structures. These challenges will need to be overcome } \\
\text { through collaborative efforts as no one unit can drive } \\
\text { digital strategy alone. }\end{array}$ \\
\hline Design for scale & $\begin{array}{l}\text { Seek to make informed tactical decisions based on the } \\
\text { understanding of the long-term, enterprise strategy. } \\
\text { Achieving scale requires adoption beyond pilots and trials } \\
\text { and often requires ongoing funding, infrastructure and } \\
\text { partners to take the initiative to new or expanding } \\
\text { communities or regions. }\end{array}$ \\
\hline Agility and flexibility & $\begin{array}{l}\text { As the priorities and requirements of the Library, } \\
\text { University and its user community change, solutions, } \\
\text { resources and services need to evolve, adapt and change } \\
\text { while minimising cost, risk and impact of changes to the } \\
\text { users, systems and environment. }\end{array}$ \\
\hline $\begin{array}{l}\text { Understand the existing } \\
\text { ecosystem }\end{array}$ & $\begin{array}{l}\text { Well designed initiatives and digital tools consider the } \\
\text { particular structures and needs that exist in each unit, }\end{array}$ \\
\hline
\end{tabular}

(C) Amy Hardy and Clare McKenzie

Address correspondence to Amy Hardy, Acting Team Leader Liaison Services, University Library, University of Wollongong, Northfields Avenue, Wollongong, NSW 2522 Australia. E-mail: amym@uow.edu.au or Clare McKenzie, Associate Director Learning \& Engagement, University Library, University of Wollongong, Northfields Avenue, Wollongong, NSW 2522 Australia. E-mail: clare_mckenzie@uow.edu.au. 


\begin{tabular}{|l|l|}
\hline & $\begin{array}{l}\text { portfolios and the University. Initiatives that do not } \\
\text { account for ecosystem changes are less likely to achieve } \\
\text { their objectives or scale. }\end{array}$ \\
\hline $\begin{array}{l}\text { Apply a University perspective } \\
\text { to service and application } \\
\text { architecture }\end{array}$ & $\begin{array}{l}\text { Look at digital strategy and innovation from the } \\
\text { perspective of developing university wide digital } \\
\text { capabilities. Seek to integrate and optimize existing } \\
\text { solutions to achieve maximum University benefit. }\end{array}$ \\
\hline
\end{tabular}

(Source: Jantti, M. 2019 - "Library Services Business Plan" presentation to Library staff, February 2019)

Within the roadmap and guided heavily by the digital first principles, there are two key areas of focus which influenced our current service model for the delivery of integrated information and digital literacies in the curriculum, particularly related to the Library goal 'Optimise digitallyenabled learning and service environments'. The first area of focus is the improved provision of self-mediated point of need access to learning resources and the second is to scope alternatives for the delivery of the StartSmart information literacy modules and hurdle quiz. Through various name changes and iterations, the compulsory first year experience program StartSmart has been the flagship for the scalable delivery of Information Literacy and academic integrity skills development to all commencing coursework students for 20 years. With the shift in focus to just in time, integrated library content for students, it was timely to review the purpose and function of this program and from 2020 StartSmart, will no longer contain any information literacy skills content, instead focusing on academic integrity expectations and requirements, led by the University's Academic Integrity Unit and aligned to a national regulatory standard (Department of Education, 2018a).

The initial impetus of these two key drivers enabled members of the Liaison Services team to delve more fully into the creation of digital alternatives, to develop online interactive tutorials and videos based on search skills, and combine digital literacies knowledge to enhance traditional information literacy concepts like peer review and Library database instruction.

This combined with the reality of the students' need or desire to learn anywhere/anytime, requires that we are targeted in our approach to integrating information and digital literacy skills into the curriculum, to reach as many students as we can at every campus, as well as distance and online only students (Maddison 2013).Course or subject material, resources and other supports, therefore, must be available or indicated at point of need. Our content must engage students where they are when they need it. Providing a recording of a lecture in the online space may be the easy option if a subject is taught both on campus and online, but this is an isolating and disengaging experience for online only students (Stone, 2017). Wherever possible we should be providing support which is embedded into the curriculum at the right time and place, that is, when students most need to utilise their information and digital literacy skills such as when they are finding information to complete assessment tasks (Maddison 2013, Stone \& O'Shea, 2019).

(C) Amy Hardy and Clare McKenzie

Address correspondence to Amy Hardy, Acting Team Leader Liaison Services, University Library, University of Wollongong, Northfields Avenue, Wollongong, NSW 2522 Australia. E-mail: amym@uow.edu.au or Clare McKenzie, Associate Director Learning \& Engagement, University Library, University of Wollongong, Northfields Avenue, Wollongong, NSW 2522 Australia. E-mail: clare_mckenzie@uow.edu.au. 
Providing easy links to timely relevant support, within learning content is an important way to point students in the right direction for the appropriate help they may need, at the right time (Stone \& O'Shea, 2019). Students need access to support material relevant at that point in time so they don't have to look in multiple places and risk getting lost or disengaged.

\section{Development of Digital Learning Objects}

Online learning offers many benefits to students, Faculty staff and other units such as the Library. For librarians a primary advantage is that it allows for the integration of scalable information and digital literacies skills instruction at point of need, to provide timely support for students in relevance to course content.

In line with the strategic institutional move to blended and online modes of delivering course content, liaison librarians in consultation with academics, have developed a suite of Digital Learning Objects (DLOs) to convey concepts and skills that were once delivered face-to-face in one shot information literacy classes. Library DLOs are developed to meet the specific needs of the UOW community, as an institution with multiple campuses and delivery modes. The Library's aim in creating DLOs is to provide scalable, sustainable solutions to students' learning needs within a changing digital environment.

The suite of DLOs includes, but is not limited to, YouTube videos and online tutorials created using the Guide on the Side (Gots) web application. DLO's are modular, chunked down and placed at point of need. They can be included in either subject or course level Moodle sites with context provided around the object by the academic. We also have DLOs embedded in database descriptions within the A-Z Database list and in some Library Guides.

The full list of public DLOs can be viewed from the Library's Finding Information Guide. The UOW EQUELLA Repository hosts all DLOs in the Library Learning Object Collection, including DLOs that are not public and are intended for specific subjects.

\section{The New Model of Engagement}

The UOW Library Liaison Services team's primary purpose is:

"To develop and deliver Library resources and services that contribute to the academic community at UOW successfully engaging in learning, teaching and research activities"

Combined with the new focus on a digital first offering and mindset, it became clear that we needed a new approach to supporting teaching and learning. As already described, this centres around the development and creation, or reuse of Digital learning objects (DLOs) which can be sustainably maintained over time to benefit as many students as possible.

In 2019, the Liaison Services team leaders developed a model to act as a blueprint for the service offering, which is critical for supporting sustainable and scalable library services that offer value to our stakeholders (Phillips, 2016) and not just a scattergun approach to the development of DLOs. Specifically, the model outlines how the Library's Liaison Services team

(C) Amy Hardy and Clare McKenzie

Address correspondence to Amy Hardy, Acting Team Leader Liaison Services, University Library, University of Wollongong, Northfields Avenue, Wollongong, NSW 2522 Australia. E-mail: amym@uow.edu.au or Clare McKenzie, Associate Director Learning \& Engagement, University Library, University of Wollongong, Northfields Avenue, Wollongong, NSW 2522 Australia. E-mail: clare_mckenzie@uow.edu.au. 
supports the sustainable and scalable integration of information and digital literacy skills into the curriculum at UOW.

There is limited literature focused on the combined scalability and sustainability of online information literacy instruction in university libraries. The existing literature is centred around embedded librarianship (Luca, 2019; Allen, 2017, Maddison 2013), and level of engagement with asynchronous learning modules (Thompson and Carrier, 2016). Allen (2017) also notes that accreditation can be satisfied by developing a well thought out plan of action for sustainable and scalable delivery of online IL instruction.

Our model seeks to engage with targeted academic staff with the aim of integrating DLOs into the curriculum at UOW in both a scalable and sustainable fashion. Members of the Liaison Services team are currently seeking to advance knowledge in this gap in the literature via a research project with the aim to evaluate our digital learning objects, and aspects of this model, for practical application at other institutions.

In order to be efficient with time and resources, and to ensure reach to students at other campuses and online, the model requires the Liaison Services team target subject coordinators of large first year subjects, and coordinators of Capstone, Honours and appropriate core postgraduate coursework subjects. The team will respond to requests for assistance from other academics as required, however, the focus of the proactive engagement is on these large cohorts in the first instance.

\section{The Conversation Framework}

Integral to the model is the conversation framework (Figure 2). Focused questions and a collaborative approach can assist with engagement and conversations with Faculty teaching staff around learning and teaching needs and greatly increase the outcomes for students (YevelsonShorsher \& Bronstein, 2018, Bapte, 2019). 
Figure 2: Conversation framework for information and digital literacy skills integration

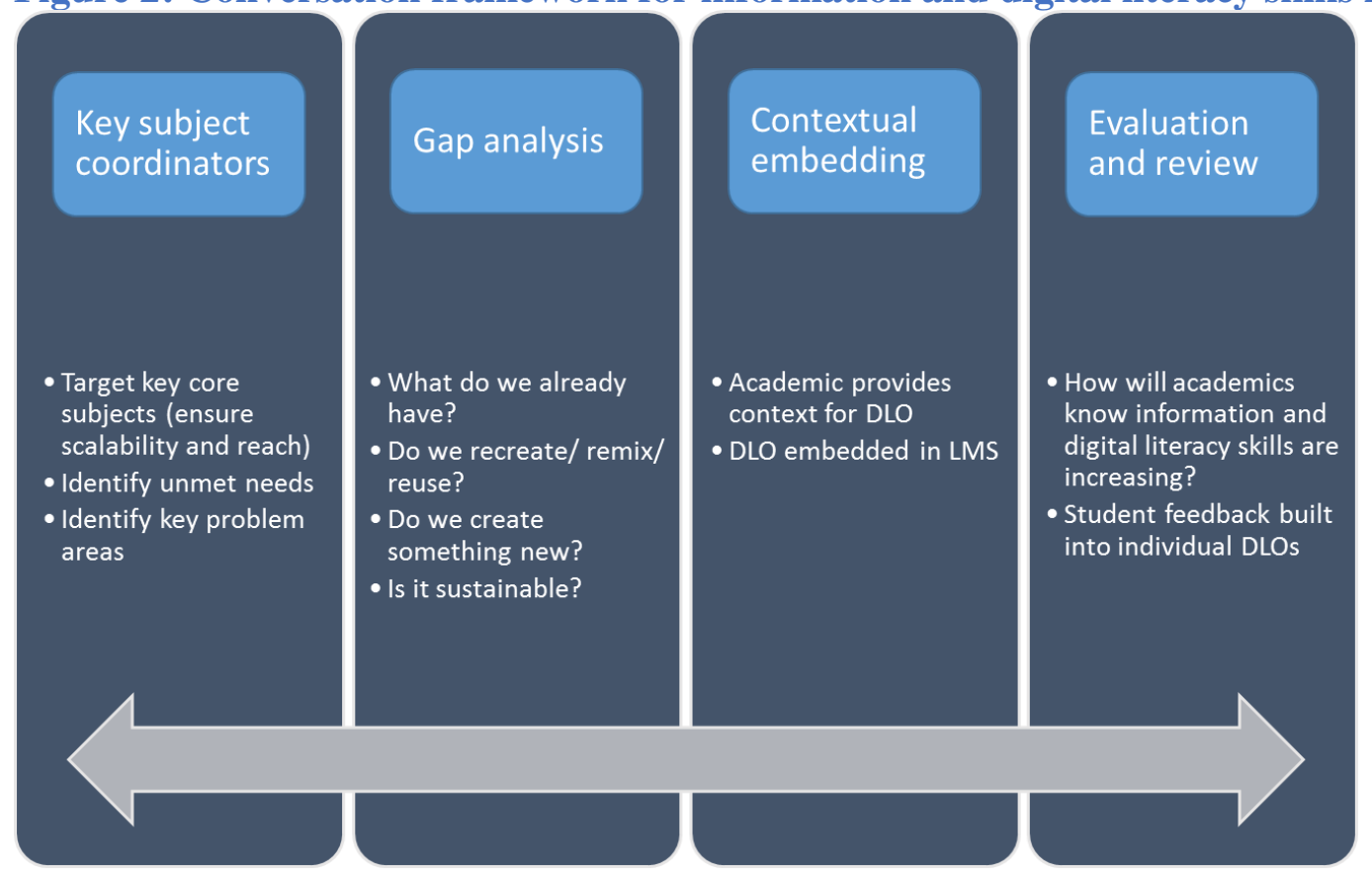

It is not the purpose of these conversations to tell academics what they need or to 'sell' them DLOs. Use of focussed questions in these meetings is designed to enable collaborative discussion with the rest of the Liaison Services team about the best approach to meeting the needs of this group of students. Importantly, the conversation can start anywhere on this spectrum, it is needs based and not necessarily a linear process.

The aim of these targeted conversations with subject coordinators is to ask open questions to discover the unmet needs of their students in relation to the skills required to find, evaluate and use information for that subject or course. We work with academics to identify the key information and digital literacy skills needs of their students, and to identify and integrate appropriate solutions into the curriculum at a point where they are most relevant to the students. In these conversations we are also seeking to identify and unpack key problem areas or 'sticking points' and apply a threshold concept approach to the development of solutions.

The conversation is then bought back to the Library team to consider solutions and conduct a gap analysis. We look at the desired information and digital literacy learning outcomes and map them to the learning objects and resources that we already have available. We use Digital Learning Object guidelines to help us decide if we develop a new DLO, or recreate, remix or reuse a resource from another institution in line with our principles that any new learning solution can be both scalable and sustainable.

Another conversation aim is to assist in suggestions for providing meaningful context to DLOs within the subject. The value of this discussion with the Subject coordinator is that we can give 
guidance about where the DLO is placed within the learning platform, and the context for the skills being learnt in relation to (for example) an assessment task.

An integral part of the conversation framework process is to explore how feedback and evaluation can be built in. Questions like 'How will you know if your students' understanding of [skill] has increased as a result of the DLO?' and 'Would you be open to me returning at the end of semester to discuss how it went?' are included. We also include feedback forms at the end of our DLOs in order to directly gather student feedback. All of this informs the ongoing review and maintenance of our DLO collection and to a certain degree forms part of the evaluation research project we are currently undertaking.

\section{Beyond Future Ready}

The combined pressures of Australian universities reliance on federal government funding, concerns about attrition, and the realities of student life today has led to our current practice in delivering information and digital literacies.

While we have been building towards this current state for some time, it is early days yet for the structured, conversation-based approach the team is taking to supporting learning and teaching through the provision of information and digital literacy learning objects. The findings from the research evaluation project currently underway will help inform future directions for the Library's service offerings in this space.

The model and conversation framework have allowed us to be both proactive and responsive to the needs of academics and students at the University of Wollongong. Through consultation with academics along the way we have been able to increase their understanding of the ways we can support their students beyond face to face classes - facilitating a true paradigm shift. This very real issue of how to meet the needs of our students wherever they are is not unique to us, but is a matter for academic libraries across the globe. 


\section{References}

Allen, S. (2017). Mapping Uncharted Territory: Launching an Online Embedded Librarian Program. Journal of Library \& Information Services in Distance Learning, 11(1-2), 251261. https://doi.org/10.1080/1533290X.2016.1193416

Bapte, V. D. (2019). Information Literacy Instruction Determining the Place of Library Professionals. DESIDOC Journal of Library \& Information Technology, 39(1), 39-46. https://doi.org/10.14429/djlit.39.1.13676

Bexley, E. (2019, August 9). Government funding will be tied to uni performance from 2020: What does this mean, and what are the challenges? Retrieved 8 October 2019, from: http://theconversation.com/government-funding-will-be-tied-to-uni-performance-from2020-what-does-this-mean-and-what-are-the-challenges-121694

Cowan, S. M. (2014). Information literacy: The battle we won that we lost? Portal: Libraries and the Academy, 14(1), 23-32. https://doi.org/10.1353/pla.2013.0049

Davis, G. (2013). The Australian idea of a university. Meanjin, 72(3).

Department of Education. (2018). Funding | Department of Education, Australian Government. Retrieved 8 October 2019, from Australian Government | Department of Education website: https://www.education.gov.au/funding

Department of Education. (2018a). Higher Education Standards Framework | Department of Education, Australian Government. Retrieved 18 November 2019, from Australian Government | Department of Education website: https://www.education.gov.au/standards-0

Department of Education and Training. (2017). FINAL REPORT - Improving retention, completion and success in higher education | Higher Education Standards Panel. Retrieved 8 October 2019, from https://docs.education.gov.au/system/files/doc/other/final_report_for_publishing.pdf

Farrell, R., \& Badke, W. (2015). Situating information literacy in the disciplines: A practical and systematic approach for academic librarians. Reference Services Review, 43(2), 319-340. https://doi.org/10.1108/RSR-11-2014-0052

Hall, S. (2011, July 2). Foundations are laid, so it's time to aim high. Illawarra Mercury; Wollongong, N.S.W., p. 11.

Luca, E. J. (2019). Reflections on an Embedded Librarianship Approach: The Challenge of Developing Disciplinary Expertise in a New Subject Area. Journal of the Australian Library and Information Association, 68(1), 78-85.

Maddison, T. (2013). Learn Where You Live: Delivering Information Literacy Instruction in a Distributed Learning Environment. Journal of Library \& Information Services in Distance Learning, 7(3), 264-277. https://doi.org/10.1080/1533290X.2013.806276

Min, B. S., \& Falvey, R. (2018). International student flows for university education and the bilateral market integration of Australia. Higher Education, 75(5), 871-889. https://doi.org/10.1007/s10734-017-0175-4

Phillips, A. (2016). Educating at scale: Sustainable library learning at the University of Melbourne. Library Management, 37(3), 149-161. https://doi.org/10.1108/LM-04-2016$\underline{0020}$

(C) Amy Hardy and Clare McKenzie

Address correspondence to Amy Hardy, Acting Team Leader Liaison Services, University Library, University of Wollongong, Northfields Avenue, Wollongong, NSW 2522 Australia. E-mail: amym@uow.edu.au or Clare McKenzie, Associate Director Learning \& Engagement, University Library, University of Wollongong, Northfields Avenue, Wollongong, NSW 2522 Australia. E-mail: clare_mckenzie@uow.edu.au. 
Stone, C., \& O'Shea, S. (2019). Older, online and first: Recommendations for retention and success. Australasian Journal of Educational Technology, 35(1). https://doi.org/10.14742/ajet.3913

Stone, C. (2017). Opportunity through online learning: Improving student access, participation and success in higher education (NCSEHE 2016 Equity Fellowship Final Report). Perth: Curtin University.

Thompson, L., \& Carrier, H. S. (2016). Scalable Equals Asynchronous and Asynchronous Equals Boring. Or Does It? Internet Reference Services Quarterly, 21(3-4), 81-92. https://doi.org/10.1080/10875301.2016.1241202

Universities Australia. (2018). 2017 Universities Australia Student Finances Survey. Retrieved 8 October 2019, from: https://www.universitiesaustralia.edu.au/wpcontent/uploads/2019/06/180713-2017-UA-Student-Finance-Survey-Report.pdf

University of Wollongong. (2017). Collection Development Policy. Retrieved 6 November 2019 from https://documents.uow.edu.au/content/groups/public/@web/@gov/documents/doc/uow23 8365.pdf

University of Wollongong. (2019). Our reputation \& experience-University of Wollongong. Retrieved 9 October 2019, from About UOW website: https://www.uow.edu.au/about/reputation/

University of Wollongong. (2019a). Statistics-University of Wollongong. Retrieved 9 October 2019, from About UOW website: https://www.uow.edu.au/about/reputation/statistics/

Weightman, A. L., Farnell, D. J. J., Morris, D., Strange, H., \& Hallam, G. (2017). A Systematic Review of Information Literacy Programs in Higher Education: Effects of Face-to-Face, Online, and Blended Formats on Student Skills and Views. Evidence Based Library and Information Practice, 12(3), 20-55. https://doi.org/10.18438/B86W90

Yevelson-Shorsher, A., \& Bronstein, J. (2018). Three Perspectives on Information Literacy in Academia: Talking to Librarians, Faculty, and Students. College \& Research Libraries, 79(4), 535-553. https://doi.org/10.5860/crl.79.4.535 